\title{
SECURITY CONSTRAINED OPTIMAL DISPATCH USING GENETIC ALGORITHMS FOR NORMAL AND EMERGENCY CONDITIONS
}

\author{
A. A. Abou El-Ela \\ M. A. Bishr \\ R. A. F. Saleh \\ T. Fetouh \\ Department of Electrical Engineering, Faculty of Engineering, Shebin El-Kom \\ Minoufiya University, Egypt
}

\begin{abstract}
This paper presents a proposed technique for security constrained optimal dispatch (SCOD) problem under normal and emergency conditions. In this technique a modified version of the genetic algorithm (GA) is used. The SCOD problem is formulated using non-linear unit cost functions and solved by the proposed technique. The results obtained using this technique are compared with those obtained using a conventional linear programming technique and with those obtained using fuzzy modeling technique.

The comparison studies are performed considering the changes in system constraints as: membership models in fuzzy technique and chromosomes in GA technique. Numerical studies of fuzzy modeling are based on the fuzzy linear programming (FLP) technique with fuzzy constraints of different shapes for their membership functions. Simulation results show that the proposed GAbased technique for SCOD is more accurate and efficient, especially with increasing the system size.

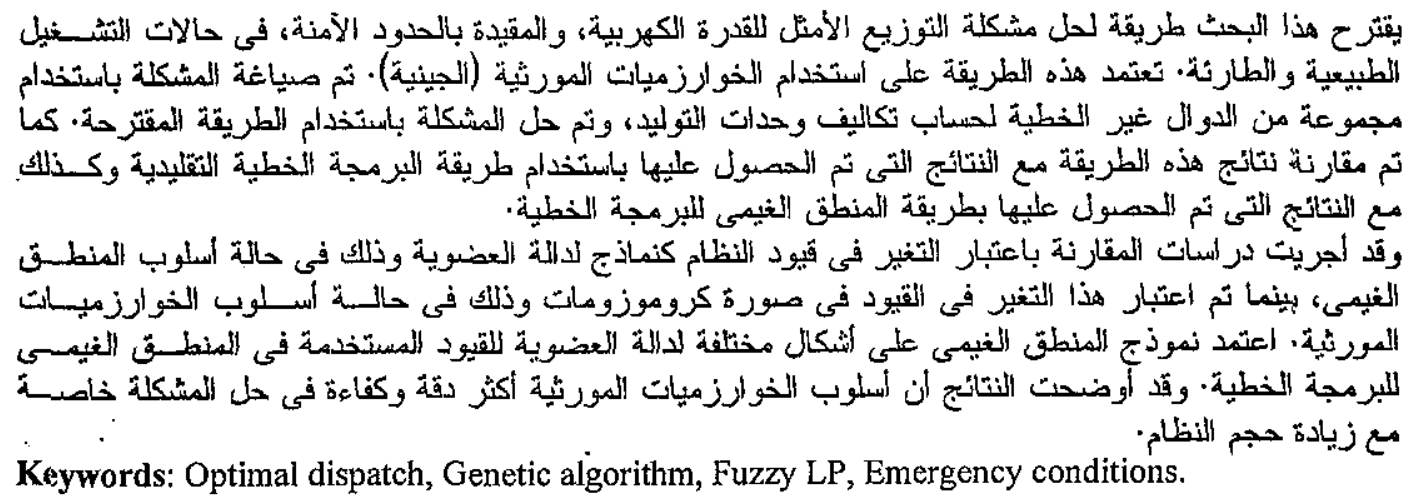

\section{INTRODUCTION}

The optimal dispatch (OD) represents one of the basic functions of energy management systems. In general, the task of $O D$ is to optimally allocate loads among on-line generating units subject to power balance, system reserve requirements and other system constraints. The problem becomes more complicated due to the non-linear nature of the objective function and constraints of real life problems. When approximating the cost functions by piecewise linear curves, many segments may be required to achieve the desired accuracy, and a rather elaborate logic for traversing the segments has to be employed [1].

Literature survey shows that the SCOD problem has been studied extensively. In Ref. [2], an approach for solution of the security constrained economical dispatch (SCED) with piecewise linear cost and 2- segments spinning reserve curves was developed. This approach was based on what the author calls, the differential algorithm and the simplex method. The basic idea is to reduce the size of the underlying linear programming (LP) problem by searching and eliminating pinned units. Some results of an implementation of this approach are reported in [3]. An L.P formulation of a multi-area system SCED is presented in [3]. While, the transmission constraints are defined with respect to the system as a whole, the reserve requirements are imposed on the levels of individual areas. Reference [4] presented preventive control actions using the fuzzy modeling of generation units, load demand and power flows in critical lines. Ref. [5] addresses different security regions that satisfy the condition of secure and economic solutions of power dispatch at different controller positions was presented. The authors in Ref. [6] proposed two types of fuzzy models, namely 
triangular and trapezoidal models to find the suitable model for each power system constraint. Reference [7] presented a hybrid method for the solution of the optimal allocation of reactive power sources based upon a modified genetic algorithm (GA) which is applied at an upper level stage and a successive linear program at a lower level stage. In Ref. [8], an improved GA was developed and applied to a least cost generation expansion planning (GEP) problem. Least cost GEP problem is concerned with a highly constrained non-linear dynamic optimization problem.

In this paper, another technique is proposed to solve SCOD problem using a GA. Simulation results demonstrate that the proposed technique is able to remove the overloads in the critical lines and to minimize the generation costs for both normal and emergency conditions.

\section{MODELING OF SECURITY CONSTRAINT OPTIMAL DISPATCH}

Let us define the procedure that enables minimization of the cost of the power injection shifts with respect to the initial economic dispatch of generating units while not losing any customer on the power grid. The costs are defined as:

$\min F_{t}=\sum_{i=1}^{N G} f_{i}\left(P G_{i}\right)=\sum_{i=1}^{N G} a_{i}+b_{i} P G_{i}+c_{i} P G_{i}{ }^{2}$

where,

$F_{t}:$ is the non-linear objective function defining the total power generation cost of the system.

$a_{i}, b_{i}$ and $c_{i}$ are the coefficients of power generation cost function.

$N G$ : is the number of generation buses.

The objective.function (1) is subject to the following constraints:

$$
\begin{aligned}
& \mathrm{PG}_{\mathrm{i}}^{\min } \leq \mathrm{PG}_{\mathrm{i}} \leq \mathrm{PG}_{\mathrm{i}}^{\max } \\
& \mathrm{PF}_{\mathrm{k}}=\left|\mathrm{D}_{\mathrm{k}, \mathrm{i}} \mathrm{PG}_{\mathrm{i}}\right| \leq \mathrm{PF}_{\mathrm{k}}^{\max } \\
& \sum_{\mathrm{i}=1}^{\mathrm{NG}} \mathrm{PG}_{i}=\sum_{\mathrm{j}=1}^{\mathrm{NL}} \mathrm{PD}_{\mathrm{j}}+\mathrm{P}_{\text {losses }}
\end{aligned}
$$

where,

$P G_{i}^{m a x}$ and $P G_{i}^{m i n}$ are the maximum and minimum of power generation at bus $i$.

$P F_{k}$ : is the power flow in line $k$.

$P F_{k}^{\max }$ : is the maximum power flow in line $k$.

$D_{k, i}$ : is the sensitivity parameter of the power flow related to the power generation.

$P D_{j}$ : is the load demand at load bus $j$.

$N L$ : $\quad$ is the number of load buses.

$P_{\text {losses }}:$ is the total power losses in the system.

\section{PROPOSED MODIFIED GA FOR SCOD}

Genetic Algorithms (GAs) are numerical optimization algorithm inspired by both natural selection and natural genetics. The algorithms are simple to understand and the required computer code is easy to write. Rather than starting from a single point within the search space, GAs are initialized with a population of guesses, which are usually random and will be spread throughout the search space. A typical algorithm then uses three operators; selection, crossover and mutation to direct the population towards convergence at the global optimum solution.

\subsection{Representation of Modified GA}

The binary code representation is used where each individual is usually encoded into a string of binary bits (chromosome). A chromosome is subdivided into genes, each gene represents a variable, consists of a binary string with length that depends on the boundary of the corresponding variable. The chromosome structure is illustrated as shown in Fig.1.

$\underbrace{\frac{1000010111100}{\text { Gene of PG1 }} \frac{000111110111}{\text { Gene of PG2 }}}_{\text {chromosome }}$

Fig. 1 Chromosome and Genes structure

\subsection{Selection}

This operation attempts to apply pressure upon the population in a manner similar to that of natural selection found in biological systems. Poorer performing individuals are weeded out and better performing individuals have a greater than average chance of promoting the information they contain within the next generation. The commonly used methods for selection are roulette wheel method and toumament method. The roulette wheel method is represented as shown in Fig. 2, where infeasible solutions (poorer performing individuals) occupy a very small arc on the wheel, while feasible solutions (which satisfy system constraints) occupy a valuable length of arc.

\subsection{Crossover}

This operation allows solutions to exchange information in a way similar to that used by a natural organism undergoing sexual reproduction. The crossover occurs when two parents exchange parts of their corresponding chromosomes. The number of chromosomes that undergo the crossover operation is determined by the crossover probability. The crossover scheme used is two points crossover as shown in Fig. 3.a. 


\subsection{Mutation}

It is used to randomly change (flip) the value of a single bit within individual strings. Mutating a binary bit means switching it from 0 to 1 or vice versa. The mutation operator is applied as shown in Fig. 3.b. This process of selection, crossover and mutation, is continued until a fixed number of generations are elapsed or some form of convergence criterion has been met.

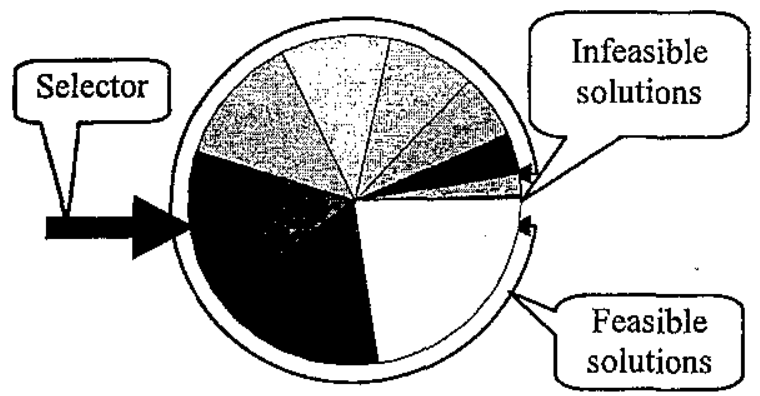

Fig. 2 The roulette wheel method

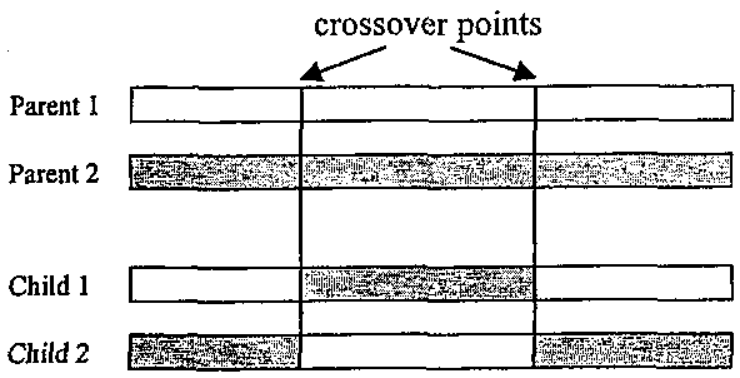

a- Crossover

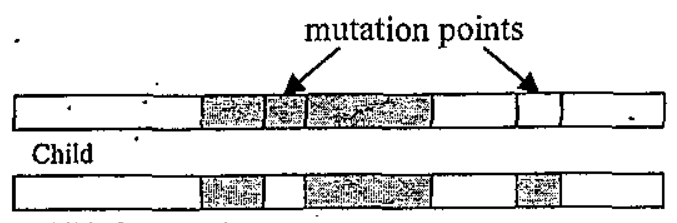

Child after mutation

b- Mutation

Fig. 3 The crossover and mutation operations

\section{PROPOSED FLP MEMBERSHIP MODELS}

The changes in membership models have an effect in the optimization problem [6]. The shape of the membership function is constructed according to the nature of variable variations.

\subsection{Modeling of Objective Function}

The objective is to minimize a certain function (Min $Z$ ). The proposed shape of fuzzy modeling is shown in Fig. 4, where the membership function $\mu(Z)$ of the generation cost can be written in the following form:

$$
\mu(z)=\left\{\begin{array}{cc}
1 & z<z_{0} \\
\left(\mathrm{z}_{1}-\mathrm{z}\right) /\left(\mathrm{z}_{1}-\mathrm{z}_{0}\right), & z_{0}<z<z_{1} \\
0 & z>z_{1}
\end{array}\right.
$$

where $Z$ is a point between $Z_{0}$ and $Z_{1}$.

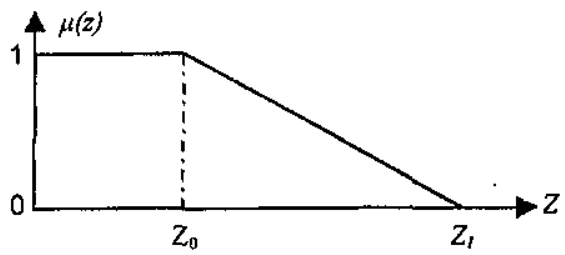

Fig. 4. Objective membership function

\subsection{Modeling of Power Generation}

The proposed shape of the power generation fuzzy membership function is shown in Fig. 5, which can be written in the following form:

$\mu(\mathrm{Pg})=\left\{\begin{array}{ccc}\left(\mathrm{Pg}_{\mathrm{g}}-\mathrm{Pg}^{\min }\right) /\left(\mathrm{Pg}^{\max }-\mathrm{Pg}^{\min }\right), \mathrm{Pg}^{\min }<\mathrm{Pg}<\mathrm{Pg}^{\max } \\ 0 & \text {, otherwise }\end{array}\right.$

where $\mathrm{Pg}$ is a point between $\mathrm{Pg}^{\text {inin }}$ and $\mathrm{Pg}^{\max }$

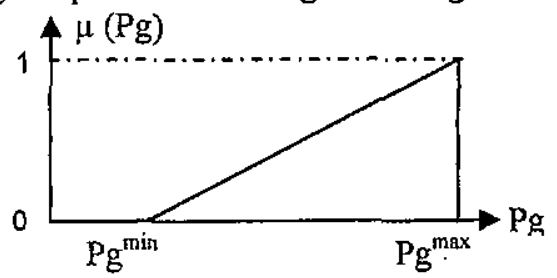

Fig. 5 Power generation membership function

\subsection{Modeling of Power Flow Constraints}

The proposed shape of the power flow fuzzy membership function is shown in Fig. 6, which can be written in the following form:

$$
\mu(\mathrm{PF})=\left\{\begin{array}{cl}
\left(\mathrm{PF}-\mathrm{PF}^{\mathrm{min}}\right) /\left(\mathrm{PF}^{\mathrm{max}}-\mathrm{PF}^{\mathrm{min}}\right) & , \mathrm{PF}^{\mathrm{min}}<\mathrm{PF}<\mathrm{PF}^{\max } \\
0 & \text {, otherwise }
\end{array}\right.
$$

where $\mathrm{PF}$ is a point between $\mathrm{PF}^{\mathrm{min}}$ and $\mathrm{PF}^{\max }$

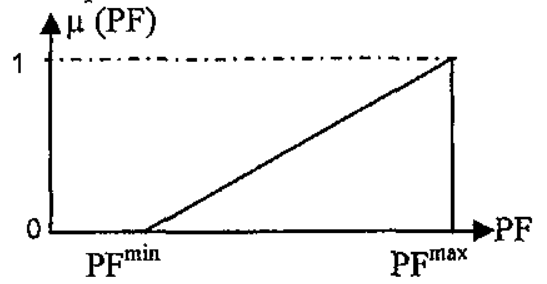

Fig. 6 Power flow membership function

Hence, the SCOD problem, as Equations (1)-(4), can be considered as a multi-objective optimization problem because the aim is to find the values of $\mathrm{Pg}$ and the degrees of membership of $\mathrm{Pg}$ and $\mathrm{PF}$ which maximize the degree of membership for objective function $\mu(\mathrm{z})$. 
This multi-objective optimization problem can be solved by $M A X \_M I N[\mu(\mathrm{z})]$, which can be written as:

$$
\begin{aligned}
& \operatorname{Max}[\operatorname{Min}(\mu(z), \mu(p g), \mu(p f), \ldots \ldots .)] \\
& \text { Or } \quad M a x \alpha \\
& \text { Subject to: } \quad \mu(Z) \geq \alpha \\
& \mu(P g) \geq \alpha \\
& \mu(P F) \geq \alpha
\end{aligned}
$$

where $\alpha \in[0,1], \alpha$ is the degree of the problem optimality.

\section{APPLICATIONS}

\subsection{Test Systems}

Three standard test systems are used to study the proposed technique for SCOD using a modified GA. The first test system contains 5 buses and 7 transmission lines (modified 5-bus test system [4]). The second system is IEEE 14-bus test system [9], while the third is IEEE 30-bus test system [9]. Tables 1 and 2 illustrate the generation and lines data for the modified 5-bus system. The critical lines are number 1 in all test systems. The maximum power flow ratings of these critical lines are equal to 45,150 and $65 \mathrm{MW}$ for the three systems, respectively. However the ratings of the other lines in the three systems are below their security limits.

Table 1 Generation bus data for 5-bus test system

\begin{tabular}{|c|c|c|c|c|}
\hline $\begin{array}{c}\text { Bus } \\
\text { No. }\end{array}$ & $\begin{array}{c}\mathrm{Pg}^{\text {mini }} \\
(\mathrm{MW})\end{array}$ & $\begin{array}{c}\mathrm{Pg}^{\max } \\
(\mathrm{MW})\end{array}$ & $\begin{array}{c}\mathrm{Pg}^{\text {initial }} \\
(\mathrm{MW})\end{array}$ & $\begin{array}{c}\text { Cost Function } \\
(\$ / \mathrm{hr})\end{array}$ \\
\hline 1 & 10 & 120 & 100 & $1.7 \mathrm{P}_{1}+0.0001 \mathrm{P}_{1}^{2}$ \\
\hline 2 & 10 & 90 & 45 & $2.3 \mathrm{P}_{2}+0.002 \mathrm{P}_{2}^{2}$ \\
\hline 5 & 10 & 60 & 40 & $2.2 \mathrm{P}_{5}+0.0015 \mathrm{P}_{5}{ }^{2}$ \\
\hline
\end{tabular}

Table 2 Line data for 5-bus test system

\begin{tabular}{|c|c|c|c|c|c|}
\hline $\begin{array}{c}\text { Line } \\
\text { No. }\end{array}$ & $\begin{array}{c}\text { From } \\
\text { bus }\end{array}$ & $\begin{array}{c}\text { To } \\
\text { bus }\end{array}$ & $\begin{array}{c}\mathrm{r}+\mathrm{j} x \\
\text { (p.u. })\end{array}$ & $\begin{array}{c}\mathrm{y} / 2 \\
\text { (p.u.) }\end{array}$ & $\begin{array}{c}\mathrm{PF}^{\text {initial }} \\
(\mathrm{MW})\end{array}$ \\
\hline 1 & 1 & 2 & $0.02+\mathrm{j} 0.06$ & 0.06 & 52.29 \\
\hline 2 & 1 & 3 & $0.08+\mathrm{j} 0.24$ & 0.05 & 33.34 \\
\hline 3 & 2 & 3 & $0.06+\mathrm{j} 0.18$ & 0.04 & 27.75 \\
\hline 4 & 4 & 2 & $0.06+\mathrm{j} 0.18$ & 0.04 & 30.09 \\
\hline 5 & 2 & 5 & $0.04+\mathrm{j} 0.12$ & 0.03 & 38.86 \\
\hline 6 & 3 & 4 & $0.01+\mathrm{j} 0.03$ & 0.02 & 13.12 \\
\hline 7 & 4 & 5 & $0.08+\mathrm{j} 0.24$ & 0.05 & -3.85 \\
\hline
\end{tabular}

* denotes overflow in line.

Two different operation conditions are considered to obtain the SCOD, which are normal and emergency conditions.

The emergency conditions that may occur in the three test systems are:

a) sudden increase in load demand.

b) unexpected outage of one line.

c) unexpected outage of units inside the generation plant.

\subsection{Results and Comments}

\subsubsection{Normal Conditions}

Tables 3, 4 and 5 show the comparison between the results obtained using four different techniques; namely the conventional linear programming technique, the FLP technique [4], the proposed FLP technique and the proposed technique using GA. In these tables, the SCOD which is computed using the proposed modified GA has most reduction in the generation cost compared with other techniques.

Table 3 Comparison between different optimization techniques for 5-bus system (load=185 MW)

\begin{tabular}{|c|c|c|c|c|}
\hline & LP & $\begin{array}{c}\text { Triangle } \\
\text { FLP [4] }\end{array}$ & $\begin{array}{c}\text { Proposed } \\
\text { FLP }\end{array}$ & $\begin{array}{c}\text { Modified } \\
\text { GA }\end{array}$ \\
\hline $\mathrm{P} 1$ & 90.2 & 76.1 & 78.9 & 90.2 \\
\hline $\mathrm{P} 2$ & 34.8 & 60 & 61.7 & 35.8 \\
\hline $\mathrm{P} 5$ & 60 & 48.9 & 44.4 & 59 \\
\hline $\mathrm{PF} 1$ & 45 & 32.48 & 34.6 & 44.98 \\
\hline Cost (\$/hr) & 380.7 & 393.1 & 391.7 & 374.1 \\
\hline Time (sec) & 0.55 & 0.66 & 0.66 & 0.99 \\
\hline
\end{tabular}

Table 4 Comparison between different optimization techniques for 14-bus system (load $=260 \mathrm{MW}$ )

\begin{tabular}{|c|c|c|c|c|}
\hline & LP & $\begin{array}{c}\text { Triangle } \\
\text { FLP[4] }\end{array}$ & $\begin{array}{c}\text { Proposed } \\
\text { FLP }\end{array}$ & $\begin{array}{c}\text { Modified } \\
\text { GA }\end{array}$ \\
\hline $\mathrm{P} 1$ & 208.1 & 188.7 & 196.8 & 208.1 \\
\hline $\mathrm{P} 2$ & 51.86 & 71.3 & 63.2 & 51.9 \\
\hline $\mathrm{PF} 1$ & 150 & 133.6 & 140.4 & 149.96 \\
\hline Cost (\$/hr) & 958.1 & 963.7 & 961.4 & 767.5 \\
\hline Time (sec) & 0.5 & 0.66 & 0.72 & 1.1 \\
\hline
\end{tabular}

Table 5 Comparison between different optimization techniques for 30 -bus system (load $=220 \mathrm{MW}$ )

\begin{tabular}{|c|c|c|c|c|}
\hline & LP & $\begin{array}{c}\text { Triangle } \\
\text { FLP [4] }\end{array}$ & $\begin{array}{c}\text { Proposed } \\
\text { FLP }\end{array}$ & $\begin{array}{c}\text { Modified } \\
\text { GA }\end{array}$ \\
\hline P1 & 10 & 52 & 53.7 & 49.1 \\
\hline P2 & 80 & 62.3 & 63.3 & 65.6 \\
\hline P3 & 39.4 & 28.9 & 31 & 21 \\
\hline P4 & 10 & 16 & 17 & 23.7 \\
\hline P5 & 30 & 25.5 & 24 & 16.5 \\
\hline P6 & 50.6 & 35.3 & 31 & 44.1 \\
\hline PF1 & -0.251 & 30.94 & 31.89 & 28.07 \\
\hline Cost (\$/hr) & 871.93 & 879.22 & 879.72 & 685.13 \\
\hline Time (sec) & 0.6 & 1.1 & 0.66 & 1.75 \\
\hline
\end{tabular}

Table 6 shows the comparison of the computational times for different optimization techniques applied on three test systems. In this table, it can be noticed that, the computation time for the proposed modified GA are around $2.3 \%$ of the time in the linear programming technique, while the computation time consumed for the proposed shape of the fuzzy membership technique is in the order of $1.2 \%$ of the time in the linear programming technique. 
Table 6 Comparison between the computational time for the different optimization technique for three test systems.

\begin{tabular}{|c|c|c|c|c|}
\hline & \multicolumn{4}{|c|}{ Computation time (sec) } \\
\cline { 2 - 5 } & L.P & $\begin{array}{c}\text { Triangle } \\
\text { FLP [4] }\end{array}$ & $\begin{array}{c}\text { Proposed } \\
\text { FLP }\end{array}$ & Modified GA \\
\hline 5-bus & 0.55 & 0.66 & 0.66 & 0.99 \\
\hline 14-bus & 0.5 & 0.66 & 0.72 & 1.1 \\
\hline 30-bus & 0.6 & 1.1 & 0.66 & 1.75 \\
\hline
\end{tabular}

Table 7 shows the comparison of the total generation costs for different techniques applied on three test systems. In this table, it can be noticed that the generation costs determined by the proposed modified GA have considerably lower values compared with that obtained by the linear programming technique and the fuzzy membership technique. On the other hand, the proposed FLP has a little reduction in the generation cost, in some cases, compared with the FLP using triangular membership functions [4].

Table 7 Comparison between generation cost for different systems

\begin{tabular}{|c|c|c|c|c|}
\hline \multirow{2}{*}{} & \multicolumn{4}{|c|}{ Generation Cost (\$/hr) } \\
\cline { 2 - 5 } & L.P & $\begin{array}{c}\text { Triangle } \\
\text { FLP [4] }\end{array}$ & $\begin{array}{c}\text { Proposed } \\
\text { FLP }\end{array}$ & $\begin{array}{c}\text { Modified } \\
\text { GA }\end{array}$ \\
\hline 5-bus & 380.7 & 393.1 & 391.7 & 374.1 \\
\hline 14-bus & 958.1 & 963.7 & 961.4 & 767.5 \\
\hline 30-bus & 871.93 & 879.22 & 879.72 & 685.13 \\
\hline
\end{tabular}

\subsubsection{Emergency conditions}

\section{- Sudden increase in load demand}

Tables 8 and 9 show the SCOD using the proposed modified GA for different loading states for the 5bus and 14-bus test systems.

In these Tables, the power flows in the critical lines are kept within their limits, and the generation costs are increased according to increasing the load demand.

Table 8 SCOD using the proposed modified GA for different loading states for 5-bus test system

\begin{tabular}{|c|c|c|c|c|c|c|}
\hline Load (MW) & 150 & 170 & 185 & 200 & 220 & 230 \\
\hline P1 & 83.02 & 87.17 & 90.2 & 92.48 & 92.5 & 92.48 \\
\hline P2 & 17.09 & 29.04 & 35.8 & 50.41 & 70.15 & 80.02 \\
\hline P3 & 49.89 & 53.79 & 59 & 57.11 & 57.35 & 57.50 \\
\hline PF1 & 44.31 & 44.47 & 44.98 & 44 & 40.72 & 39.1 \\
\hline
\end{tabular}

\begin{tabular}{|c|c|c|c|c|c|c|}
\hline Cost $(\$ / \mathrm{hr})$ & 295.21 & 340.1 & 374.07 & 409.63 & 460.4 & 486.38 \\
\hline
\end{tabular}

\section{- Unexpected outage of transmission line}

Tables 10 and 11 show the SCOD computed using the proposed modified GA technique for different lines outage compared with the load flow (LF) using the Newton-Raphson method for 5-bus and 14-bus test systems. In these tables, overflows in the critical lines are removed using the proposed modified GA technique.

Table 9 SCOD using the proposed modified GA for different loading states for 14-bus test system

\begin{tabular}{|c|c|c|c|c|c|c|}
\hline Load (MW) & 220 & 240 & 260 & 270 & 280 & 285 \\
\hline P1 & 203.4 & 205.8 & 208.1 & 209.3 & 210.5 & 211 \\
\hline P2 & 16.6 & 34.2 & 51.9 & 60.7 & 69.5 & 74 \\
\hline PF1 & 148.93 & 149.1 & 149.43 & 149.65 & 149.89 & 149.94 \\
\hline Cost (\$/hr) & 616.1 & 689.2 & 767.5 & 808.55 & 850.9 & 872.7 \\
\hline
\end{tabular}

Table 10 SCOD for different line outage for 5-bus test system (load=185 MW)

\begin{tabular}{|c|c|c|c|c|c|c|}
\hline Line Outage & \multicolumn{2}{|c|}{1} & \multicolumn{2}{c|}{2} & \multicolumn{2}{c|}{6} \\
\hline Technique & LF & GA & LF & GA & LF & GA \\
\hline P1 & 90.2 & 58.1 & 90.2 & 58.1 & 90.2 & 85.6 \\
\hline P2 & 35.8 & 70 & 35.8 & 70 & 35.8 & 40 \\
\hline P3 & 59 & 56.9 & 59 & 56.9 & 59 & 59.4 \\
\hline PF1 & - & -- & $76.89^{*}$ & 44.46 & $48.26^{*}$ & 44.16 \\
\hline PF2 & $78.41^{*}$ & 44.64 & $-\cdots$ & $\cdots$ & 26.96 & 26.37 \\
\hline
\end{tabular}

Table. 11 SCOD for different line outage for 14-bus test system (load $=260 \mathrm{MW})$

\begin{tabular}{|c|c|c|c|c|c|c|}
\hline Line Outage & \multicolumn{2}{|c|}{7} & \multicolumn{2}{c|}{6} & \multicolumn{2}{c|}{10} \\
\hline Technique & L.F & GA & L.F & GA & L.F & GA \\
\hline P1 & 208.1 & 185.4 & 208.1 & 202.7 & 208.1 & 203.5 \\
\hline P2 & 51.9 & 74.6 & 51.9 & 57.3 & 51.9 & 56.5 \\
\hline PF1 & $169.68^{*}$ & 150 & $154.5^{*}$ & 149.9 & $153.84^{*}$ & 149.9 \\
\hline PF7 & --- & --- & 46.1 & 27.7 & 94.71 & 94.3 \\
\hline
\end{tabular}

\section{- Unexpected outage of some units inside the} generation plant

Figures 7 and 8 show the SCOD using the proposed modified GA for different percentage outage of generation plants 1 and 3 for the 5-bus test system, respectively. From these figures, the power generation at bus 2 (PG2) is increased according to an increase in the percentage outage of power generations, while the generation costs are increased.
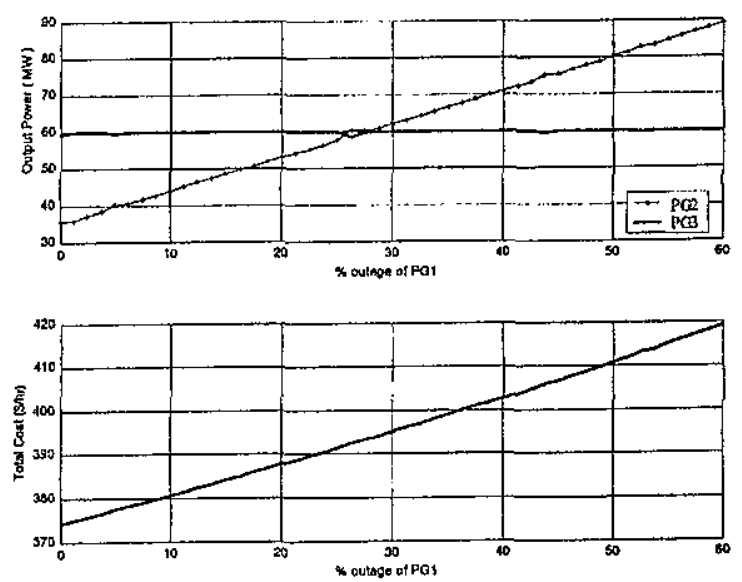

Fig. 7 The SCOD using the proposed modified GA for different percentages outage of plant 1 

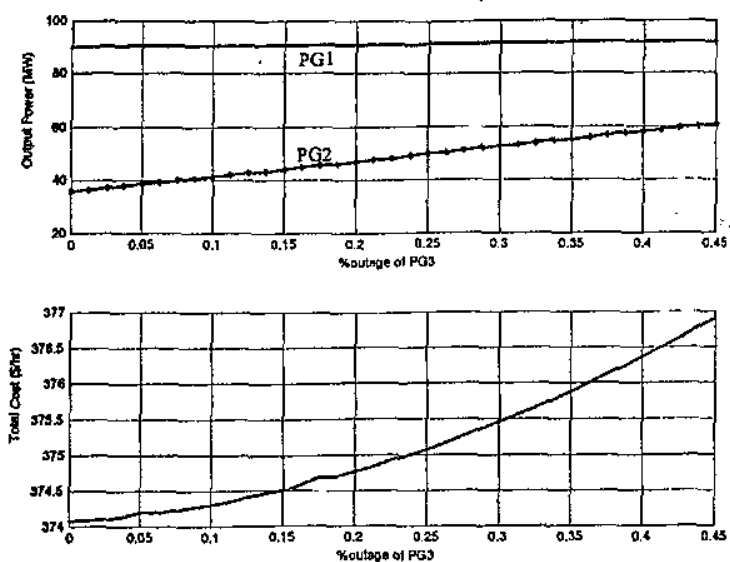

Fig. 8 The SCOD using the proposed modified GA for different percentages outage of plant 3 .

\section{Notes}

- Simulation is carried on $\mathrm{P} 3-1.2 \mathrm{GHz}$ processor, by MATLAB 6.5 software package.

- Parameters for GA are selected through experiments as following:

\begin{tabular}{|l|c|}
\hline Population size & 80 \\
\hline Probability of Crossover & $50 \%$ \\
\hline Probability of Mutation & $5 \%$ \\
\hline Number of Crossover Points & 2 \\
\hline Termination Precision 0.01 for 10 population \\
\hline Roulette Wheel Selection with Elitism Strategy. \\
\hline
\end{tabular}

\section{CONCLUSIONS}

This paper presents two efficient, accurate and optimum proposed techniques to remove the overflows in the critical lines for both normal and emergency conditions. The first proposed modified GA leads to a lower generation costs for normal condition, while all the power flows in the critical lines are kept within their permissible limits. The other proposed shape of the fuzzy membership function results in a little reduction in generation cost compared with the triangle shape of the fuzzy membership [4], while the power flow in all transmission lines are within the security limits. In the emergency condition, the proposed modified GA is efficiently applied to remove the insecure operation for different emergency conditions.

These proposed techniques fulfill the practical requirements of the electricity utility companies, which prefer faster and accurate methods to remedy, as quickly as possible, many potentially dangerous operating conditions. Therefore, the proposed techniques represent a potential tool to aid the power system operators in the on-line environment.

\section{REFERENCES}

[1] B.Stoh and J.L Marinho, "Linear Programming for Power System Network Security Applications", IEEE Trans. on Power Apparatus and Systems, Vol. PAS-98, No.3, pp. 837-848, May/June 1979.

[2] R. Lugtu, "Security Constrained Economic Dispatch", IEEE Trans. on Power Apparatus and Systems, Vol. PAS-98, No.1, pp. 270-274, Jan/Feb. 1979.

[3] A. J. Elacqua and S. L. Corey, "Security Constrained Economic Dispatch at The Network Power Pool", IEEE Trans. on Power Apparatus and Systems, Vol. PAS-101, No.8, pp. 2876-2883, Aug. 1982.

[4] A. A. Abou El-Ela, M. A. Bishr, S. Allam and R. El-sehiemy, " Optimal Preventive Control Actions Using Multi-Objective Fuzzy Linear Programming Technique ", printed in Journal of Electrical Power Systems Research (EPSR), U.S.A , 2005.

[5] A. A. Abou El-Ela, M. A. Bishr, S. Allam and R. El-sehiemy, "Optimal Security Region Using Multi-Models of Fuzzy Rule Based Controllers in Power Systems Operations ", Engineering Research Journal (ERJ), Minoufiya University, Faculty of Engineering, Egypt, pp.307-314 October 2004.

[6] A. A. Abou El-Ela, M. A. Bishr, S. Allam and R. El-sehiemy, " Optimal Power Dispatch Using Different Fuzzy Constraints Modeling in Power Systems ", Al-Azhar Engineering Eighth International Conference (AEIC 2004). Faculty of Engineering, Al-Azhar University, Cairo, Egypt, 24-27 December 2004.

[7] A. J. Urdaneta, J. F. Gomez, E. Sorrentino, L. Flores and R. Diaz, "A Hybrid Genetic Algorithm for Optimal Reactive Power Planning Based Upon Successive Linear Programming ", IEEE Trans. on Power Systems, Vol. 14, No.4, pp. 1292-1298, November 1999

[8] J. B. Park, Y. M. Park, J. R. Won and K. Y. Lee, "An Improved Genetic Algorithm for Generation Expansion Planning ", IEEE Trans. on Power Systems, Vol. 15, No.3, pp. 916-922, August 2000.

[9] Washington University Website: www.ee.washington.edu/research/pstcal 